\title{
A FOGUEIRA QUE QUEIMOU A ALMA ONTEM INCINERA A EDUCAÇÃO HOJE: A PERSEGUIÇÃO AOS ESTUDOS DE GÊNERO'1
}

\author{
Renata Lewandowski Montagnoli² \\ Liane Vizzotto ${ }^{3}$
}

\begin{abstract}
Resumo
O objetivo deste artigo é analisar as ações e os seus julgados no Supremo Tribunal Federal para apontar os pontos convergentes a favor dos estudos sobre gênero utilizados pelos ministros da Suprema Corte em suas decisões. A análise de dez Arguições de Descumprimento de Preceito Fundamental ou Ação Direta de Inconstitucionalidade, já julgadas pela Suprema Corte, constituem a base documental da pesquisa. A grosso modo, os achados mostram a legalidade dos estudos de gênero na escola, ancorada na Carta Constitucional Federal (1988).

Palavra-chave: Gênero; Legalidade; Supremo Tribunal Federal; Educação.

\section{LA HOGUERA QUE QUEMÓ EL ALMA AYER INCINERA LA EDUCACIÓN HOY: LA PERSECUCIÓN DE LOS ESTUDIOS DE GÉNERO}

\section{Resumen}

El objetivo de este artículo es analizar las acciones y sus sentencias en la Corte Suprema para señalar los puntos convergentes a favor de los estudios de género utilizados por los ministros de la Corte Suprema en sus decisiones. El análisis de diez (Irguiese) de incumplimiento de un Precepto Fundamental o Acción Directa de Inconstitucionalidad, ya juzgadas por el tribunal Supremo (o Corte Suprema), constituyen la base documental de la investigación. Los resultados muestran la legalidad de los estudios de género en la escuela, anclados en la carta Constitucional Federal (1988).

Palabra chave: Género; Legalidad; Corte Suprema (Tribunal Supremo); Educación.

\section{SOULS BURNED AT THE STAKE IN THE PAST, EDUCATION BURNS AT THE STAKE TODAY: A "WITCH HUNT" AGAINST GENDER STUDIES}

\begin{abstract}
The purpose of this paper is to analyze the lawsuits and the decisions issued by the Federal Supreme Court to point out the converging points in favor of gender studies used by the Supreme Court ministers in their decisions. The analysis of ten Non-compliance With a Fundamental Precept or Direct Unconstitutionality Action, in already decided cases by the Supreme Court, constitute the documentary basis of the research. Roughly speaking, the findings show the legality of gender studies at school, anchored in the Federal Constitution (1988).

Keyword: Gender; Legality; Federal Supreme Court; Education.
\end{abstract}

\footnotetext{
1 Artigo recebido em 19/10/2020. Primeira avaliação em 27/10/2020. Segunda avaliação em 31/10/2020. Aprovado em 14/12/2020. Publicado em 25/02/2021.

DOI: https://doi.org/10.22409/tn.v19i38.46595

2 Mestranda do Mestrado Acadêmico em Educação do Instituto Federal Catarinense - IFC (Campus Camboriú/SC). E-mail: renata.lemon@hotmail.com; ORCID:0000-0001-5371-0522.

Lattes: http://lattes.cnpq.br/7551558761757070

${ }^{3}$ Doutora em Educação pela Universidade do Vale do Rio dos Sinos (Unisinos)I. Professora do IFC (Campus Camboriú/SC). E-mail: liane.vizzotto@ifc.edu.br; ORCID: 0000-0002-8002-981X.

Lattes: http://lattes.cnpq.br/4735083599333817.
} 


\section{Introdução}

Em 24 de abril de 2020, depois de um longo processo de perseguição e luta, o Supremo Tribunal Federal (STF) garantiu a constitucionalidade e o direito de pluralidade de ideias para os estudos sobre gênero e diversidade nas escolas. $O$ tema estava em discussão jurídica devido aos recursos impetrados no poder Judiciário máximo do país, para que fosse julgada a legalidade da proibição nas leis municipais/estaduais e nos planos de educação de temas relacionados com os estudos de gênero, tais como: diversidade de gênero, identidade de gênero e relações de gênero.

Para essa análise, vale usar das palavras de Tomaz Tadeu da Silva (2014, p. 81), o qual diz que "[...] na disputa pela identidade, está envolvida uma disputa mais ampla por outros recursos simbólicos e materiais da sociedade".

Nesse espaço de poder, podemos entender, segundo Joan Scott (1989, p. 21), "[...] conexões explícitas entre gênero e poder, mas eles não são mais que uma parte da minha definição de gênero como uma forma primária de dar significado às relações de poder". Diante das disputas de poder e de impasses jurídicos, o caso que levou o Supremo a julgar o tema foi a Arguição de Descumprimento de Preceito Fundamental (ADPF) 4 457, referente à Lei municipal 1.516/2015 5 da cidade de Novo Gama, em Goiás, que proibia a abordagem de gênero e sexualidade nas escolas públicas da cidade. Os 11 ministros da Corte foram unânimes sobre a necessidade de se discutir questões de gênero na escola, e, segundo o relator do caso, ministro Alexandre de Moraes, os princípios atinentes à liberdade, conforme preceitua a Constituição Federal (CF/1988), "[...] não se direcionam apenas a proteger as opiniões supostamente verdadeiras, admiráveis ou convencionais, mas também aquelas eventualmente não compartilhada pelas maiorias" (STF, 2020a, p. 2)

\footnotetext{
${ }^{4}$ Esta ação está prevista no art. 102, $\S 1^{\circ}$ da CF, tendo sido regulamentada pela Lei $n^{\circ}$ 9.882/1999. "A ADPF vem completar o sistema de controle de constitucionalidade concentrado, uma vez que a competência para sua apreciação é originária e exclusiva do Supremo Tribunal Federal". Tem como objeto "[...] a possibilidade de impugnação de atos normativos municipais em face da Constituição Federal e o cabimento da ação quando houver controvérsia envolvendo direito pré-constitucional [...], podendo, por meio dela, ser impugnado qualquer ato do Poder Público de que resulte lesão ou ameaça de lesão a preceito fundamental decorrente da Constituição Federal". As decisões do STF em sede de ADPF nortearão o juízo sobre a legitimidade ou a ilegitimidade de atos de teor idêntico editados pelas diversas entidades federadas. (PAULO; ALEXANDRINO, 2017, p. 852/853).

${ }^{5}$ Lei 1.516 , de 30 de junho de 2015. Que versa sobre a proibição de material com informação sobre ideologia de gênero nas escolas municipais de Novo Gama - GO.
} 
A discussão jurídica desse tema veio à tona a partir do momento em que movimentos conservadores e reacionários da sociedade civil iniciaram uma campanha de perseguição e eliminação dos estudos sobre gênero do currículo escolar, além de promover um movimento de "caça às bruxas"6 contra os/as professores e professoras que ousassem discutir essa temática em sala de aula. De acordo com Cunha (2016, p. 3), "[...] o currículo da Educação Básica, particularmente das escolas públicas, é objeto de ação modeladora que visa frear os processos de secularização da cultura e de laicidade do Estado". Para o autor, isso ocorre mediante dois movimentos, a saber, um de contenção, outro de imposição. Ambos constroem um projeto de educação reacionária, visto que se opõem às mudanças sociais em curso e se esforçam para restabelecer situações ultrapassadas (CUNHA, 2016).

Essa campanha ecoou na sociedade e ganhou força, dando origem ao movimento Escola Sem Partido 7 . A mobilização de grupos conservadores, dentre eles o Escola sem Partido, conseguiu que a temática gênero fosse retirada de muitos planos de educação, seja nas esferas municipais, estaduais e nacional. A alegação utilizada por esses grupos é de que estão em defesa da família, da moral e dos bons costumes cristãos, algo que, segundo eles, o gênero busca destruir.

Sob essa ótica, temos a ideia de uma normatividade cristalizada, que deve se sobressair em relação à minoria. Sobre isso, Miranda (1995, p. 95) escreve: "[...] o irrestrito domínio da maioria poderia vulnerar o conteúdo essencial daqueles direitos, tal como o princípio da liberdade poderia recusar qualquer decisão política sobre a sua modulação". Portanto, os propagadores dessa cruzada contra o mal contemporâneo querem impor através da força (seja política ou jurídica) suas crenças, uma vez que consideram que representam uma maioria.

\footnotetext{
${ }^{6}$ No período medieval, foram criados os Tribunais da Santa Inquisição pela Igreja Católica, os quais tinham por objetivo julgar os casos de heresia. Nesse período, criou-se no imaginário coletivo a ideia da bruxa maligna, que propagava o mal contra os seguidores de Deus, por isso, deveria ser caçada, julgada, condenada e queimada viva. Usamos esse fato para a analogia contemporânea de "caça às bruxas", que, aqui, representa a perseguição aos estudos de gênero e aos docentes que trabalham com essa temática.

${ }^{7}$ O Movimento Escola Sem Partido surgiu em 2004, a partir de um grupo de pessoas liderado pelo exprocurador de justiça do estado de São Paulo, Miguel Nagib, que almeja o controle, a vigilância sobre escolas e educadores, bem como sobre o currículo escolar. O movimento tem inspiração em movimentos norte-americanos que combatem posições ideológicas e temas do multiculturalismo, principalmente os estudos de gênero. O movimento tem um endereço eletrônico no qual propaga suas ideias, indica livros, divulga vídeos e denúncias contra escolas e docentes. Site Escola Sem Partido. Disponível em: <https://www.escolasempartido.org/>. Acesso em: 12 out. 2020.
} 
No sentido de realizar uma pesquisa documental sobre as ações no STF que tratam da retirada das questões de gênero dos planos de educação, este trabalho tem por objetivo analisar as ações judiciais ${ }^{8}$ sobre o tema que chegaram até a Suprema Corte e os julgados que Ihes foram dados.

Neste artigo, os documentos referem-se a dez ações, entre elas sete ADPF e três $\mathrm{ADI}^{9}$, já julgadas pelo STF. Salientamos que outras ações, de igual teor, ainda estão em fase de análise pela Suprema Corte. Sendo assim, esses documentos compõem o material empírico de análise, pois "[...] representam uma fonte natural de informação [...]" (LÜDKE; ANDRÉ, 1986, p. 39). O estudo das legislações, ora elencadas, não pode ser compreendido fora de sua dimensão prática, pois se corre o risco de ocultar elementos importantes da totalidade e, por consequência, impedir a sua compreensão (TORRIGLIA; ORTIGARA, 2014).

As implicações decorrentes da aprovação ou não de legislações acerca de diversos assuntos resulta na consolidação de políticas educacionais, que, como formas jurídicas e ideológicas, "[...] não podem ser analisadas fora do movimento dialético do real, em suas determinações concretas" (TORRIGLIA; ORTIGARA, 2014, p. 188). Desse modo, o conteúdo das políticas, considerando cada uma na sua especificidade, "[...] carrega normas e orientações para efetivar comportamentos sociais necessários para sustentar o modo de produção na atualidade, o capitalismo" (TORRIGLIA; ORTIGARA, 2014, p. 189).

$\mathrm{Na}$ construção desta pesquisa, o trabalho se concentrou nas ações que foram protocoladas no STF no período entre 2016 e 2019 e que já foram julgadas, ou que já tiveram alguma manifestação por parte da Suprema Corte. A pesquisa foi realizada no site do STF, sendo encontradas 15 ações (ADPF ou ADI) que versam sobre implantação do Programa Escola Sem Partido ou da proibição dos estudos de gênero nas escolas das redes públicas de ensino. Desse total, dez ações contestam leis aprovadas em diferentes municípios ou estados brasileiros, sendo três somente do estado de Alagoas (já julgadas). As ações foram protocoladas por requerentes

\footnotetext{
8 É importante esclarecer que a legitimidade ativa para as ações que versam sobre controle concentrado de constitucionalidade (ADPF, $A D I, A D O, A D C)$ é restrita às pessoas identificadas no artigo 103 da Constituição Federal. Em razão da especificidade do assunto, esse tipo de ação compreende a exclusividade da competência para instauração e julgamento ao STF.

9 "A Ação Direta de Inconstitucionalidade (ADI) é a ação típica do controle abstrato brasileiro, tendo por escopo a defesa da ordem jurídica, mediante a apreciação, na esfera federal da constitucionalidade, em tese, de lei ou ato normativo, federal ou estadual, em face das regras e princípios constantes explícita ou implicitamente na Constituição da República" (PAULO; ALEXANDRINO, 2017, p. 782).
} 
que representam diferentes instituições/órgãos, assim distribuídas: sete ações movidas pelo Procurador-Geral da República; uma pela Confederação Nacional dos Trabalhadores em Estabelecimentos de Ensino (CONTEE); três pela Confederação Nacional dos Trabalhadores em Educação (CNTE); uma pelo Partido Democrático Trabalhista (PDT); uma pelo Partido Comunista do Brasil (PCdoB); e duas pelo Partido Socialismo e Liberdade (PSOL). Os julgamentos das ações analisadas ocorreram entre 24/04/2020 e 21/08/2020.

Quanto à organização, este artigo apresenta reflexões a partir de duas seções. A primeira discorre sobre as primeiras leis aprovadas que proíbem o estudo da temática gênero e que foram questionadas no STF e apresenta um levantamento feito sobre o processo de perseguição aos estudos de gênero instituídos por grupos civis e religiosos. Na segunda seção, analisa-se os julgados do STF quanto às dez ações que versam sobre a proibição do trabalho datemática gênero nas escolas.

\section{A caça às bruxas, à ciência e aos docentes}

Até a chegada do julgamento da Arguição de Descumprimento de Preceito Fundamental 457 (ADPF) (BRASIL/STF, 2020a) no dia 24/04/2020, muita coisa aconteceu e muitas lutas foram travadas, tanto no campo educacional quanto no cenário social e político. Em fevereiro de 2020, o ministro relator do caso, Alexandre de Moraes, já havia dado uma liminar ${ }^{10}$ para suspender a Lei 1.516/2015, que versa sobre a proibição da divulgação de material com informação sobre ideologia de gênero nas escolas municipais de Novo Gama - GO (NOVO GAMA, 2015).

Mesmo a Suprema Corte expedindo liminares semelhantes a essa para outros casos que chegaram à Corte máxima do país, muitos políticos se aliaram aos movimentos de combate às questões de gênero. Muitos daqueles que advogam a favor desses movimentos de retirada desse estudo dos currículos estão apoiados em igrejas cristãs, onde alguns de seus líderes vociferam contra a temática com o discurso de que o gênero tem por objetivo destruir a família brasileira. Um exemplo desse combate religioso ao gênero pode ser visto no documento "A ideologia do

\footnotetext{
10 "[...] liminar é aquilo que se situa no início, na porta, no limiar [...]. Rigorosamente, liminar é só o provimento que se emite inaudita altera parte, antes de qualquer manifestação do demandado e até mesmo antes de sua citação" (DIDIER, 2008, p. 615).
} 
gênero: seus perigos e alcances", da Conferência Episcopal Peruana realizada na cidade de Lima (Peru) em abril de 1998:

[...] existem muitas pessoas que talvez por falta de informação ainda não compreenderam a nova proposta e os perigosos alcances da mesma. Vale a pena, pois, conhecer esta „perspectiva do gênero" que - segundo informações fidedignas - atualmente não apenas está ganhando força nos países desenvolvidos como também, ao que parece, começa a se infiltrar no nosso meio. Basta rever alguns materiais educativos difundidos não só nos colégios do país como ainda em prestigiosas universidades. (CONFERÊNCIA EPISCOPAL PERUANA, 1998, p. 15).

No mesmo caminho, segue o discurso do pastor evangélico e Deputado Federal Silas Malafaia, que, em um evento político em São Paulo, em agosto de 2017, fez um discurso deixando claro que:

"Quem quiser fazer graça na eleição para o politicamente correto,
para a ideologia de gênero, casamento gay, legalização das drogas e
aborto, vai embora, segue seu caminho", afirmou Malafaia em evento
na zona norte da capital paulista que reuniu líderes evangélicos.
"Não vamos negociar nossos valores. Não vamos negociar em
nenhuma eleição", acrescentou o pastor, que classificou a ideologia
de gênero como uma "engenharia do diabo feita para destruir
famílias"11.

A partir do discurso desses religiosos, podemos levantar alguns questionamentos importantes no que diz respeito aos valores e conceitos defendidos por eles, como sendo valores de toda nação. Precisamos pensar, segundo Pinha (2016, p. 18-19), “[...] nas singularidades e no respeito pelas diferenças étnicas, religiosas, sexuais das diversas sociedades. Isto é, uma concepção de cidadania pautada, fundamentalmente, na noção de pluralidade". Outros questionamentos podem ser feitos, como: É o Brasil um país majoritariamente cristão? Qual é a representação de família que hoje temos em nosso país?

Quando falamos de família, precisamos levar em consideração que, no nosso país, hoje, apenas $42 \%$ das famílias representam aquilo que é chamado por alguns de "família tradicional", constituída por pai, mãe e filhos, segundo dados da Pesquisa

\footnotetext{
11 Reportagem escrita por Pedro Venceslau e Eduardo Laguna (17.08.2017). O acesso a ela é online, por isso, não é possível identificar um número da página. Disponível em:https://exame.com/brasil/malafaia-diz-que-evangelicos-nao-negociarao-ideologia-de-genero/. Acesso em 18 set. 2020.
} 
Nacional por Amostra de Domicílios (Pnad, 2015) ${ }^{12}$. De acordo com Cunha (2009, p. 418), esse estereótipo de família:

[...] tem sido a idealização maior dos grupos conservadores, que supõem em geral uma forma familiar específica (pai, mãe e filhos em convivência duradoura) [...] nuclear pequeno-burguesa estaria supostamente dotada de valores positivos, crença que não resiste a mais elementar análise objetiva.

Precisamos, então, discutir essa concepção hegemônica de família que não condiz mais com a realidade nacional, e, mesmo com dados científicos/estatísticos que comprovam a mudança da constituição familiar, existem grupos que não consideram e negam a existência dessa nova realidade. Esses grupos conservadores levam em consideração o modelo de uma família patriarcal, branca, cristã, de classe média e urbana. Essa é a representação de um grupo que detém o poder econômico, político e social e que se utiliza dele para que suas pautas continuem sendo atendidas e colocadas em prática pelo Estado.

Nesse cabo de guerra pelo poder, a escola foi o campo de disputa escolhido por ser o espaço de frequência significativa das crianças e jovens, portanto, os guardiões dessa moral cristã investiram-se da indumentária dos cavaleiros medievais da proteção contra o mal e de tudo aquilo que atente contra os costumes. A partir do discurso de que o mal deve ser combatido, a cientificidade dos conteúdos acabou por dar espaço para pautas religiosas e morais, que nada representam o saber que se espera de uma escola. Isso porque:

A educação escolar compete corroborar o desenvolvimento do pensamento teórico, uma vez que o conceito, na exata acepção do termo, eleva a mera vivência à condição de saber sobre o vivido, isto é, permite avançar da experiência ao entendimento daquilo que a sustenta - condição imprescindível para as ações intencionais (MARTINS, 2013, p. 304).

A escola tem por finalidade desenvolver junto aos educandos os conhecimentos já testados e comprovados cientificamente, que levaram homens e

\footnotetext{
12 A Pesquisa Nacional por Amostra de Domicílios (Pnad) "Investiga características gerais da população, algumas anualmente, outras eventualmente, de acordo com a necessidade do País para suprir a falta de informações sobre a população brasileira durante o período intercensitário, e estudar temas insuficientemente investigados ou não contemplados nos censos demográficos". Disponível em:http://www.sei.ba.gov. br/index.php?option=com content\&view=article\&id=2199\&ltemid=458.

Acesso em: 12 out. 2020.
} 
mulheres ao avanço da ciência e da civilização. Sobre essa mudança social e a educação, Brandão (2007, p. 79) avalia:

\begin{abstract}
A ideia de que a educação não serve apenas à sociedade, ou à pessoa na sociedade, mas à mudança social e à formação consequente de sujeitos e agentes na/da mudança social, pode não estar escrita de maneira direta nas „leis do ensino". Afinal, as leis quase sempre são escritas por quem pensa que nem elas nem o mundo vão mudar um dia. Mas as suas consequências podem aparecer indiretamente.
\end{abstract}

Não é à toa que muitas legislações educacionais não levam em conta as demandas das escolas, mas sim dos grupos que detêm o poder e que, por muitas vezes, comprometem profundamente o desenvolvimento da educação. A mudança social perpassa por uma sociedade mais justa, humana e fraterna que respeita todos os indivíduos dentro de suas especificidades, com suas singularidades e na sua completude e incompletude. Quando pensamos na questão da diversidade religiosa dos sujeitos, é preciso lembrar que esta faz parte da subjetividade, desse modo, deve ficar a cargo das igrejas e das famílias, não da escola, sendo, portanto, obrigação do Estado o respeito a todas as crenças e o direito à não crença de seus cidadãos, permitindo que todos e todas manifestem suas opiniões, orientações e opções. Entender isso parece ser difícil para alguns grupos, pois, durante muito tempo em nosso país, vendeu-se a ideia de um país majoritariamente cristão (católico), e as igrejas criaram suas próprias escolas para propagar sua fé, quando não escolas públicas, que, mesmo legalmente sendo laicas, professavam a fé católica de modo geral e obrigavam os estudantes a também seguir os ritos dessa religião/igreja.

Não é difícil encontrar, nos dias de hoje, ainda, escolas que realizam rezas e orações no início das aulas, celebrações cristãs, ou que tenham em seus espaços comuns imagens sacras. Um exemplo dessa prática é o caso do município gaúcho de Xangri-Lá. A Câmara de Vereadores da cidade promulgou, no dia 21 de agosto de 2020, a Lei 2.166, que torna obrigatória a leitura da Bíblia no início das aulas (matutino e vespertino) nas escolas públicas do município (CÂMARA DE XANGRILÁ, 2020).

Esse tipo de prática é normalizado pelas pessoas de um modo geral, isso porque há, no imaginário coletivo, a ideia de que ela é inofensiva. Então, podemos questionar: o que aconteceria se em uma escola pública um gestor colocasse num 
espaço comum a imagem de alguma divindade relacionada a uma religião de matriz africana? Isso seria bem visto? Muito provavelmente não seria algo aceito pela comunidade e ainda usariam o argumento de que o Estado é laico e não pode estabelecer uma crença em prejuízo de outras. Nesse contexto, no entanto, percebese que o Estado é laico somente em certas relações, em certas situações de poder. Isso demonstra uma face de intolerância,que tem

[...] sua origem em uma predisposição comum a todos os humanos, a de impor suas próprias crenças, suas próprias convicções, desde que disponham, ao mesmo tempo, do poder de impor e da crença na legitimidade desse poder. Dois componentes são necessários à intolerância: a desaprovação das crenças e das convicções do outro e o poder de impedir que esse outro leve sua vida como bem entende (RICCEUR, 1997, p. 20).

A intolerância religiosa, a desconsideração da ciência, a polarização e a criminalização dos estudos sobre gênero ganharam força em toda a América Latina no final dos anos de 1990. Segundo a antropóloga feminista francesa Françoise Héritier (1997), a intolerância é o desejo de um grupo de manter a sua união, quando este se sente ameaçado por aqueles excluídos anteriormente.

No Brasil, essa pauta marcada pela intolerância ganhou força nos primeiros anos de 2000, quando foi criado o movimento Escola Sem Partido, que conseguiu angariar adeptos e propagar suas demandas conservadoras pelo país. Aqueles que antes não demostravam interesse algum para com a escola, principalmente a pública, começaram a advogar por ela, prezando pela sua organização curricular e a manutenção dos privilégios e direitos daqueles que sempre tiveram o poder. Dessa forma, a escola passou a ser o centro de vigilância, no sentido de impedir que quaisquer debates sobre temas julgados inadequados fossem discutidos.

O discurso conservador ganhou apoio entre alguns religiosos cristãos que, do dia para a noite, passaram a lutar pela educação, não qualquer educação, mas sim uma educação que vá ao encontro de suas práticas e explicitem a ideia de "nós" e "os outros":

O outro necessariamente diferente e, portanto, o estabelecimento de critérios de reconhecimento, a lógica da diferença não deveria acarretar, automaticamente, nem hierarquia, nem desconfiança, nem ódio, nem a exploração, nem a violência (HÉRITIER, 1997, p. 27). 
Nesse movimento de demarcação do nós e dos outros e de articulação contra o gênero na escola, os documentos oficiais da educação nacional, estadual e municipal passaram a ser vistoriados e questionados, assim como os docentes e suas práticas pedagógicas, processo que se assemelhou à caça às bruxas do período das trevas, quando aqueles que ousavam questionar as práticas da Igreja Católica eram levados para Tribunais da Inquisição. Os tribunais dessa inquisição contemporânea passaram a ser midiáticos: o docente dogmático e subversivo que ousasse trabalhar com as questões de gênero em sala de aula era/é desmoralizado, demonizado e combatido moralmente, tendo seu trabalho desqualificado devido à sua atuação a favor de um mundo melhor. Conforme as palavras de Brandão (2007, p. 110), "Acreditar que o ato humano de educar existe tanto no trabalho pedagógico que ensina na escola quanto no ato político que luta na rua por um outro tipo de escola, para um outro tipo de mundo". Os professores e suas ideias de igualdade e de justiça social passaram a ser vistos como um perigo para a escola e para a sociedade.

Os debates contra o gênero ficaram mais acalorados quando da promulgação, em 2014, do Plano Nacional de Educação (PNE), Lei 13.005, de 26 de junho de 2014. Nesse documento, foi retirada toda e qualquer menção às questões de gênero. Os planos municipais e estaduais sofreram a mesma pressão de grupos religiosos ligados às igrejas evangélicas, à igreja católica e aos grupos de cidadãos que alegam não querer que seus filhos aprendam sobre a famigerada ideologia de gênero nas escolas. Esse discurso demonstra total desconhecimento sobre o tema, além de constatar o desrespeito aos princípios democráticos constitucionais.

Em dezembro de 2017, é promulgada a Base Nacional Comum Curricular (BNCC), documento que regulamenta o currículo nacional por meio de uma base comum de aprendizagens, conhecimentos, competências e habilidades a serem desenvolvidas em cada etapa do processo educacional. Esse documento nacional não faz menção às questões de gênero, negligenciando esse tema, diferentemente do que ocorria com os Parâmetros Curriculares Nacionais (PCNs/1997). Nele, os temas transversais abordados são: ética, saúde, meio ambiente, pluralidade cultural e orientação sexual. Essa foi uma grande derrocada para a educação nacional, pois retrocede em muito nas conquistas sobre o tema. À vista disso, não dialogar sobre as questões de gênero é simplesmente fechar os olhos para as demandas e 
problemáticas que envolvem o tema; é varrer a questão para debaixo do tapete, como se negligenciá-la fosse a solução.

\section{Quando o estudo de gênero vira caso de justiça}

O caso da cidade de Novo Gama (Arguição de Descumprimento de Preceito Fundamental 457) foi o primeiro a ser julgado dentre as 15 ações que versam sobre a proibição dos estudos sobre o gênero que chegaram ao STF no período de 2016 a 2019. Outras ações não chegaram à Suprema Corte, mas tramitam na Procuradoria Federal dos Direitos do Cidadão, Procuradoria-Geral da União e Ministério Público, os quais já se manifestaram contra leis que coíbem os estudos de gênero nas escolas.

Das quinze ações que tramitam no STF, sete corresponderam a municípios localizados na região Sul [Paranaguá (PR), Foz do Iguaçu (PR), Cascavel (PR), Santa Cruz de Monte Castelo (PR), Londrina (PR), Tubarão (SC) e Blumenau (SC)], um da região Sudeste [Ipatinga (MG)], um da região Norte [Palmas (TO)], um da região Centro-Oeste [Novo Gama (GO)] e três da região Nordeste [três ADls correspondentes ao estado de Alagoas, Garanhuns (PE) e Petrolina (PE)]. O que dez dessas quinze ações têm em comum é que os ministros do STF já se manifestaram por meio de liminares de suspensão de parte ou da integralidade das leis que foram aprovadas contra as questões de gênero, além de já terem sido julgadas e consideradas inconstitucionais pela corte. Nos pareceres, os ministros estabeleceram o direito ao desenvolvimento de atividades pedagógicas sobre gênero. Para os magistrados da Suprema Corte, as leis que proíbem os estudos de gênero ferem preceitos constitucionais e direitos garantidos na Lei de Diretrizes e Bases da Educação Nacional (LDB), como coloca o Ministro Barroso em dos seus pareceres:

[...] as bases do ensino dizem respeito aos alicerces que servem de apoio à educação. „Ocorre que a Constituição estabelece expressamente como diretrizes para a organização da educação a promoção do pleno desenvolvimento da pessoa, do desenvolvimento humanístico do país, do pluralismo de ideias, bem como da liberdade de ensinar e de aprender", afirmou (STF, 2018). 
O fundamento jurídico dos outros ministros em seus votos nos demais casos segue o mesmo argumento, portanto, é ponto pacífico que, entre os magistrados, a proibição dos estudos de gênero nas escolas fere os princípios fundamentais da Constituição Federal (1988), das leis que regem a nossa educação, além de acordos internacionais dos quais o Brasil é signatário. Portanto, fica a pergunta levantada por Brandão (2007, p. 98-99):

Se a educação é determinada fora do poder de controle comunitário dos seus participantes, educandos e educadores diretos, por que participar dela, da educação que existe no sistema escolar criado e controlado por um sistema político dominante?

No caso deste estudo, os poderes que constituem o Estado parecem entrar em contradição, ou seja, os Legislativos municipais/estaduais criam e aprovam leis que vedam os estudos de gênero, sendo necessário que outro poder - agora o Judiciário - movimente seu órgão de controle concentrado de constitucionalidade, o STF, para julgar ações de sua competência e barrar a continuidade de atos que estão em desacordo com a Constituição Federal em vigor no país.

Em cada um dos casos que aguardam julgamento no STF, está implícita a ideia de que gênero é uma ideologia que deve ser combatida e proibida no espaço escolar. De acordo com esse raciocínio, em 2016, o município de Palmas (TO) instituiu uma lei que proibia o ensino sobre sexualidade e gênero na rede pública municipal. Quando a Arguição de Descumprimento de Preceito Fundamental (ADPF) 465 foi analisada no Supremo pelo ministro Luís Roberto Barroso, este concedeu uma liminar que suspendeu parte do artigo $1^{\circ}$ do Plano Municipal de Educação, Lei $2.243 / 2016^{13}$, argumentando que a lei municipal não pode estar em conflito com a lei maior. O trecho revogado, segundo o que se extrai de reportagem veiculada na imprensa local ${ }^{14}$, dizia respeito à proibição da discussão e à utilização de material didático e paradidático sobre a ideologia ou teoria de gênero, bem como a

\footnotetext{
${ }^{13}$ Lei Municipal $n^{\circ}$ 2.243/2016, de 23 de março de 2016, que versa sobre a alteração da Lei $n^{\circ} 2.238$, na Meta 5, as redações das estratégias 5.24 e 5.26 vedando a discussão e a utilização de material didático e paradidático sobre a ideologia ou teoria de gênero, sexualidade e erotização.

${ }^{14} \mathrm{Na}$ reportagem intitulada "Prefeitura de Palmas se manifesta sobre liminar do STF sobre suspensão aos efeitos de lei municipal"; a Prefeitura diz respeitar a decisão. Disponível em: https://www.justocantins.com.br/noticias-do-estado-46631-prefeitura-de-palmas-se-manifesta-sobreliminar-do-stf-sobre-suspensao-aos-efeitos-de-lei-municipal.html. Acesso em 7 out. 2020.
} 
permissão de atos e comportamentos que induzam à referida temática, bem como os assuntos ligados à sexualidade e à erotização.

Em 2016, um deputado estadual de Alagoas propôs um projeto de lei posteriormente aprovado com a identificação de Lei 7.800/2016 - que instituiu o programa Escola Livre e a proibição de ensino de sexualidade nas escolas do estado nordestino. Segundo Penna (2016, p. 57),

[...] devido à mudança de nome, os opositores das propostas do movimento escola sem partido e os professores de Alagoas nem ao menos sabiam da tramitação do projeto até que ele fosse aprovado por unanimidade e todos identificassem sua real origem. A polêmica ganhou força quando o governador do estado vetou o projeto, alegando que era inconstitucional. A assembleia, algumas semanas depois, derrubou o veto e promulgou a Lei n. 7.800 , em 5 de maio de 2016. O MEC posicionou-se através de nota oficial contra o projeto e informou que entrará com uma ação de inconstitucionalidade.

No mesmo ano, o Plenário do STF analisou a lei alagoana, e, segundo o ministro relator, Luís Roberto Barroso:

Não tratar de gênero e de orientação sexual no âmbito do ensino não suprime o gênero e a orientação sexual da experiência humana. Apenas contribui para a desinformação das crianças e dos jovens a respeito de tais temas e para a perpetuação de estigmas e do sofrimento que deles decorre (STF, 2020b).

Novamente, os magistrados demonstraram de forma legal e ética a importância dos estudos sobre gênero para o pleno desenvolvimento do indivíduo e para o desenvolvimento de uma sociedade mais humana.

Chegaram na Suprema Corte em 2017 seis ações sobre o tema, sendo elas dos municípios de: Paranaguá (PR), Cascavel (PR), Blumenau (SC), Tubarão (SC), Ipatinga (MG) e Novo Gama (GO). No caso da cidade paranaense de Paranaguá, o procurador-geral da República Rodrigo Janot ajuizou no STF a ADPF 461 contra a Lei municipal 3.468/2015, artigo $3^{\circ}$, que veda políticas de ensino sobre diversidade de gênero e orientação sexual. Segundo o procurador-geral,

[...] as normas, ao proibirem qualquer abordagem de temas ligados à sexualidade pelas políticas de ensino, reafirmam uma inexistente equivalência entre sexo e gênero e ignoram quaisquer realidades distintas da orientação sexual heteroafetiva, o que contraria dispositivos da Constituição Federal de 1988 (STF, 2017a). 
relator da ADPF, ministro Luís Roberto Barroso, determinou a suspensão dos efeitos da lei municipal, ressaltando ainda que "A transexualidade e a homossexualidade são um fato da vida que não deixará de existir por sua negação e que independe do querer das pessoas" (STF, 2017a).

Também foram suspensas outras leis municipais, tais como: Lei 6.496/2015, do município de Cascavel (ADPF 460); Lei Complementar 994/2015, de Blumenau (ADPF 462); Lei 2.243/2016, de Palmas (ADPF 465); e Lei 3.491/2015, de Ipatinga (ADPF 467). Para o Procurador-Geral da República, as normas

[...] também ferem o direito constitucional à igualdade, segundo o qual todos são iguais perante a lei, sem distinção de natureza alguma. Se gênero é categoria que concorre para explicar a diversidade sexual, igualdade de gênero é princípio constitucional que reconhece essa diversidade e proíbe qualquer forma de discriminação lesiva. Ele sustenta ainda que, ao pretender vedar que escolas utilizem material didático que articule discussões sobre gênero, às normas atacadas contrariam princípios conformadores da educação brasileira, em especial as liberdades constitucionais de aprender, ensinar, pesquisar e divulgar a cultura, o pensamento, a arte e o saber; o pluralismo de ideias e de concepções pedagógicas. Esses princípios asseguram que o ambiente escolar seja pluralista e democrático quanto a ideias e concepções pedagógicas, o que impossibilita que determinados temas sejam, a priori, banidos dos estabelecimentos escolares, ainda que mediante iniciativa legislativa (STF, 2017b).

Em 2018, os ministros avaliaram a Arguição de Descumprimento de Preceito Fundamental (ADPF) 526, referente à emenda da Lei Orgânica Municipal № 47 do município de Foz do Iguaçu (FOZ DO IGUAÇU, 2018) ${ }^{15}$. Segundo o ministro Barroso, citado no Manual de defesa contra a censura nas escolas (2018, p.30):

Por óbvio, tratar de tais temas não implica pretender influenciar os alunos, praticar doutrinação sobre o assunto ou introduzir práticas sexuais. Significa ajudá-los a compreender a sexualidade e protegêlos contra a discriminação e a violência.

Voltando a atenção para o estado de Santa Catarina, é perceptível que a "caça às bruxas" fez o seu trabalho no estado catarinense também. O PEE - Plano

\footnotetext{
${ }^{15}$ A emenda a Lei Orgânica no 47 , de 03 de maio de 2018, da cidade de Foz do Iguaçu (PR), versa sobre a proibição da adoção e/ou divulgação de políticas de ensino que tendam a aplicar a ideologia de gênero nas instituições de ensino da rede municipal. Disponível em: https://leismunicipais.com.br/a/pr/f/foz-do-iguacu/emenda-a-lei-organica/2018/5/47/emenda-a-leiorganica-n-47-2018-acrescenta-dispositivo-a-lei-organica-do-municipio-de-foz-do-iguacu-vedando-aadocao-e-ou-divulgacao-de-politicas-de-ensino-que-tendam-a-aplicar-a-ideologia-de-genero. Acesso em: 10 out. 2020.
} 
Estadual de Educação (2015-2024), Lei 16.794/2015 (SANTA CATARINA, 2015b), de 14 de dezembro, apresenta uma única vez a palavra gênero, e essa menção faz referência a gêneros alimentícios, o que em muito difere da versão de 16/06/2015, na qual a palavra gênero aparecia dez vezes. Esse documento de 2015 tinha, inclusive, metas e estratégias relacionadas às questões de gênero nos diversos níveis de ensino. Nessa versão, na meta 1, a estratégia 1.17 estabelecia:

Implementar espaços de interatividade considerando a diversidade étnica, de identidade de gênero, de gênero e sociocultural, tais como: brinquedoteca, ludoteca, biblioteca infantil e parque infantil (SANTA CATARINA, 2015a, p. 103).

Já a meta 11, estratégia 11.12, dispunha que se deveria "Adotar políticas afirmativas para reduzir as desigualdades étnico-raciais, regionais e de gênero, no acesso e permanência na educação profissional técnica de nível médio" (SANTA CATARINA, 2015a, p. 127). Percebe-se que há uma significativa perda para a educação de Santa Catarina com a aprovação de um plano cuja vigência é para uma década. Nesse período, caso não haja revisão para incluir os estudos de gênero, a temática permanecerá silenciada.

No ano de 2019, a polêmica levantada em Santa Catarina relacionava-se à aprovação do Currículo Base da Educação Infantil e do Ensino Fundamental do Território Catarinense. ${ }^{16}$ Esse currículo já vinha recebendo críticas desde 2015, devido às questões de gênero que estavam presentes. A Base Estadual só veio a ser promulgada em 2019, no governo de Carlos Moisés (PSL). A partir das notícias veiculadas na mídia, ficou evidente que a bancada conservadora da Assembleia Legislativa do Estado de Santa Catarina (ALESC) realizou uma feroz campanha contra a contemplação das questões de gênero no documento estadual.

Em vídeo divulgado nas redes sociais na noite desta quarta-feira, o governador Carlos Moisés da Silva (PSL) afirmou que vai pedir a retirada de expressões ligadas a identidade de gênero e diversidade do Currículo de Base da Educação Infantil e Fundamental do Território Catarinense. O assunto foi alvo de pressão de deputados

\footnotetext{
${ }^{16}$ Resolução CEE/SC № 070, de 17 de junho de 2019, que versa sobre a instituição e orientação para a implementação do Currículo Base da Educação Infantil e do Ensino Fundamental do Território Catarinense e normatiza a adequação à Base Nacional Comum Curricular dos currículos e propostas pedagógicas da Educação Infantil e do Ensino Fundamental no âmbito do Sistema Estadual de Educação de Santa Catarina. Disponível em: http://www.sed.sc.gov.br/professores-e-gestores/30440curriculo-base-da-educacao-infantil-e-do-ensino-fundamental-do-territorio-catarinense-3. Acesso em: 7 out. 2010.
} 
estaduais, que pedem a retirada dos termos do plano e alegam que a inclusão seria uma "proposta ideológica" (LAURINDO, 2019a).

Segundo o deputado Ismael do Santos (PSD), um dos deputados defensores da retirada do tema gênero do documento base estadual, a "[...] proposta ideológica [...] visa à [...] desconstrução do conceito da família e a erotização precoce [...]" vem desde 2015 e, portanto, deve ser retirada do documento (LAURINDO, 2019b). O discurso do parlamentar na tribuna foi endossado por outros legisladores, tais como: Maurício Eskudlark (PL), Ricardo Alba e Ana Caroline Campagnolo (ambos do PSL).

Toda a indignação dos parlamentares faz referência a dois pontos específicos do documento, com mais de 490 páginas, que menciona relações de gênero, identidade de gênero e diversidade. A primeira menção questionada diz respeito às relações de gênero e de diversidade sexual na página 43 , num tópico que pergunta quem são os sujeitos dadiversidade, tendo como resposta o seguinte:

Os sujeitos da diversidade "somos todos nós", mas há de destacarem-se os grupos que vivenciaram processos de preconceito e discriminação. A Lei de Diretrizes e Bases da Educação Nacional (Lei № 9.394, de 20 de dezembro de 1996) obriga o ensino de conteúdos históricos nas escolas: os afro-brasileiros e indígenas (BRASIL, 1996). De acordo com as Diretrizes Curriculares Nacionais para a Educação em Direitos Humanos (2012) isso significa que "(...) todas as pessoas, independente do seu sexo, origem nacional, étnicoracial, de condições econômicas, sociais ou culturais; de suas escolhas de credo; orientação sexual; identidade de gênero; faixa etária, pessoas com deficiência, altas habilidades/superdotação, transtornos globais e do desenvolvimento, têm a possibilidade de usufruírem de uma educação não discriminatória e democrática" (SANTA CATARINA, 2019, p. 43).

A análise dessa manifestação deixa evidente que a intenção da escrita é deixar registrada a importância dos direitos humanos, das comunidades tradicionais, do respeito à diversidade sexual e as relações de gênero, algo que faz parte dos princípios de civilidade de uma sociedade. $O$ item foi mantido na versão final assinada pelo governador do estado. O mesmo não aconteceu com a segunda menção a gênero questionada pelos parlamentares. Na página 393 do documento, no quadro sobre conhecimentos e habilidades a serem desenvolvidas por alunos do $8^{\circ}$ ano do Ensino Fundamental, mais especificamente no tópico "vida e evolução dentro das múltiplas dimensões da sexualidade humana", havia a expressão Identidade de gênero, e essa parte foi suprimida do documento na sua versão final (SANTA CATARINA, 2019, p. 393). 
Essa polaridade em torno de dois itens num documento tão amplo e desenvolvido por mais de 550 profissionais de educação demonstra como os interesses e a relações de poder estão em jogo nas esferas educacionais, campo de grande destaque dessas pessoas que criminalizam os estudos de gênero.

O caso do estado catarinense não chegou ao plenário do Supremo, pois não criou lei que proíba os estudos de gênero, contudo, em seus documentos norteadores, também não as discutiu, deixando um vácuo educacional extremamente prejudicial para o debate sobre diversidade, igualdade ecidadania.

A partir da pesquisa realizada para este trabalho, podemos afirmar que as leis municipais/estaduais e os planos educacionais não podem agir com demagogia, colocando em suas laudas a importância da democracia, da participação cidadã para a construção de uma sociedade mais justa, igualitária, humana e ao mesmo tempo transparecer sua intolerância quanto às temáticas que envolvem os excluídos, os marginalizados. James Mursell (1955, p. 3) já discorria sobre essa questão no século passado, e, hoje, mesmo tantas décadas depois, sua análise continua atual e totalmente pertinente:

Se as escolas de uma sociedade democrática não existem e não
funcionam para manter e expandir a democracia, então, ou são
socialmente inúteis, ou são socialmente perigosas. Na melhor das
hipóteses, educarão pessoas que se limitarão a viver a sua vida e a
ganhar o pão, insensíveis às obrigações da cidadania, em particular,
e ao modo de vida democrático, em geral... E, muito provavelmente,
educarão as pessoas para serem inimigas da democracia - pessoas
que cairão nas garras dos demagogos, apoiarão determinados
movimentos e reunir-se-ão em torno de líderes hostis ao modo de
vida democrático. Tais escolas ou são fúteis ou são subversivas.
Não têm qualquer razão legítima de existência.

Entre 24/04/2020 e 21/08/2020, o STF já havia julgado como inconstitucionais dez leis (ou fragmentos de leis) que versam sobre a proibição dos estudos de gênero nas escolas, sendo elas: Lei 1.516/2015 de Novo Gama (ADPF 457); Lei 3.941/2015 de Ipatinga (ADPF 467); Lei 7.800/2016 do estado de Alagoas (ADI 5537, ADI 6038, ADI 5580); Lei 2.243/2016 de Palmas (ADPF 465); Lei 3.468/2015 de Paranaguá (ADPF 461); Lei 6.496/2015 de Cascavel (ADPF 460); Lei Orgânica, Emenda 55/2018 de Londrina (ADPF 600); e Lei Orgânica, Emenda 47/2018 de Foz do Iguaçu (ADPF 526). Em todos os julgados a decisão para a inconstitucionalidade das leis foi unânime entre os ministros, e, em todas as decisões, eles ressaltaram a 
importância de uma educação para a cidadania, diversidade, que respeite o pluralismo de ideias e desenvolvimento pleno dos sujeitos.

A decisão do STF só reafirmou aquilo que está impresso em nossa Carta Magna: laicidade do ensino, pluralismo de ideias e a liberdade de cátedra, além das designações expressas nas convenções internacionais das quais o Brasil é signatário, entre elas: Pacto Internacional sobre os Direitos Econômicos, Social e Culturais (1966) e o Protocolo Adicional de São Salvador à Convenção Americana sobre Direitos Humanos (1988). Essas convenções tratam de questões relacionadas à promoção dos direitos humanos, da justiça social e o fim das desigualdades, sejam elas de gênero, raça/etnia ou religiosas.

A Organização das Nações Unidas (ONU), dentre os 17 Objetivos para o Desenvolvimento Sustentável (ODS), no objetivo 5, Igualdade de Gênero, busca alcançar a igualdade de gênero e empoderar todas as mulheres e meninas. ${ }^{17}$ Portanto, há preocupação global com as questões de gênero, com o fim das desigualdades e com as violências de gênero. Por isso, precisamos pensar que:

[...] a regra da maioria só pode ser justificada se os homens são iguais e eles só são iguais na posse de direitos. Uma política de igualdade, portanto, precisa ser uma política preocupada com direitos. Consequentemente, a regra da maioria, só é legitima se na prática a maioria respeita os direitos da minoria (BERNS, 1986, p. 285).

Por conta disso, é de extrema importância enfatizar que vivemos em um país democrático e que tem no seu conjunto de leis a proposição do Estado de Direito, o qual deve respeitar todos os cidadãos e primar por uma escola democrática e pautada na cientificidade, e não em crenças religiosas ou morais de grupos que querem, por meio da violência, perseguição e ignorância impor o seu posicionamento. Como disse Bobbio (1993, p. 117), "[...] sem respeito às liberdades civis, a participação do povo no poder político é um engano, e sem essa participação popular no poder estatal, as liberdades civis têm poucas probabilidades de durar".

\footnotetext{
17 Segundo o site Estratégia ODS: "Os Objetivos de Desenvolvimento Sustentável (ODS) são uma agenda mundial adotada durante a Cúpula das Nações Unidas sobre o Desenvolvimento Sustentável em setembro de 2015 composta por 17 objetivos e 169 metas a serem atingidos até 2030", que dentre as ações previstas há referência à igualdade de gênero. Disponível em: https://estrategiaods.org.br/o-que-sao-os-ods/. Acesso em: 10 out. 2020.
} 
Pensando nas palavras de Bobbio sobre liberdades e participação civil, se revela necessário compreender que é direito da sociedade civil se manifestar contra aquilo que se apresenta como injusto e ilegal, porém, não contra a ciência e os preceitos legais de uma constituição, pois, se assim o fizerem, estão agindo de forma antidemocrática, quando não autoritária.

Desse modo, a sociedade, quer seja por meio de seus representantes eleitos, quer seja por intermédio das pessoas da sociedade civil, precisa entender que os estudos de gênero como conhecimento escolar, além de terem legalidade jurídica, fazem parte da constituição humana e promovem o desenvolvimento de uma sociedade mais plena, justa e igualitária para todos e todas. Também precisa assimilar que não temos mais espaço para preconceito, racismo, sexismo, misoginia, transfobia, homofobia e tantas outras formas de violência carregadas de crenças e valores de exclusão e de julgamentos religiosos que em nada representam as leis e a laicidade do nosso Estado.

\section{Considerações finais}

Depois de tantas lutas travadas e disputas de ordem micro e macro, em 24 de abril de 2020, o STF finalmente julgou como inconstitucional uma ação tão polêmica envolvendo o estudo das questões de gênero, deixando professores e profissionais de educação resguardados no seu direito de liberdade de cátedra para ensinar e aprender. Todo esse movimento contrário aos estudos sobre gênero promoveu um retrocesso no desenvolvimento dessas temáticas na educação escolar, uma vez que em vários municípios e até em um estado do Brasil foram criadas leis que proibiam o estudo da temática.

Anteriormente a essa data, o STF havia concedido liminares para a suspensão de artigos de leis ou leis em sua íntegra que tratassem da proibição da temática gênero nas escolas. Porém, a primeira decisão da corte favorável ao estudo de gênero (em abril de 2020) abriu precedente para todas as demais ações no Supremo que tratam de conteúdos relacionados à famigerada ideologia de gênero e ao movimento Escola Sem Partido. Os ministros e ministras do Supremo Tribunal Federal decidiram, num placar de $11 \times 0$, que a lei do município goiano de Novo Gama é inconstitucional, pois fere a competência privativa da União em 
legislar diretrizes e bases da educação nacional, a laicidade do Estado, o direito à igualdade, o direito de divulgar o pensamento e o direito à liberdade de aprender, ensinar e pesquisar. Em 20 de fevereiro de 2020, o relator da Arguição de Descumprimento de Preceito Fundamental 457, ministro Alexandre de Moraes, já havia concedido suspensão imediata da Lei 1.516 de Novo Gama até que houvesse o julgamento definitivo. Agora não cabe mais recurso e, em definitivo, os governos estaduais e municipais não poderão calar as demandas que envolvem as questões de gênero.

Em novembro de 2018, mais de 60 entidades uniram-se para lançar o Manual de Defesa contra a Censura nas escolas (2018), que serve de auxílio a professores e profissionais de educação, e é também uma resposta contundente aos movimentos conservadores e suas cartilhas de perseguição e discriminação. Existem hoje no Brasil mais de 180 Projetos de Leis (PL) ou leis que proíbem o estudo da temática gênero nas escolas ou que instituem normas baseadas nos fundamentos do movimento Escola Sem Partido (MANUAL de defesa contra a censura na escola, 2018, p. 15).

A articulação de entidades educacionais demonstra que a defesa da ciência, do Estado laico e da pluralidade de ideias está presente e que os interesses de um grupo que prega a intolerância e o preconceito não podem se sobressair ao saber, à liberdade de cátedra, à cientificidade e à busca por uma sociedade mais justa.

Os movimentos conservadores de manutenção do status quo buscam homogeneizar a sociedade a partir do seu ponto de vista, impondo suas regras, normas e moral. Todavia, ainda vivemos num país livre e que deve respeitar a todos e a todas como cidadãos de direitos, de tal forma que, nesse caminho, a educação tem papel fundamental no processo de humanização da sociedade, não podendo ser talhada ou tolhida, seja pelas amarras, seja pelas fogueiras da intolerância.

\section{Referências}

BERNS, W. A Constituição assegura esses direitos? In: GOLDWIN, Robert A; SCHAMBRA, William A. A constituição norte-americana. Rio de Janeiro: Forense Universitária, 1986. p. 263-287.

BOBBIO, N. Igualdad y libertad. Barcelona: Paidós, 1993. 
BRANDÃO, C R. O que é Educação. 49 reimpressão. São Paulo: Brasiliense, Coleção primeiros passos, 2007.

BRASIL. Constituição da República Federativa do Brasil de 1988. Disponível em: http://www.planalto.gov.br/ccivil_03/constituicao/constituicaocompilado.htm. Acesso em: 14 abr. 2016.

Decreto no 591, de 06 de julho de 1992. Promulga o Pacto Internacional sobre Direitos Econômicos, Sociais e Culturais. Promulgação. Disponível em: http://www.planalto.gov.br/ccivil_03/decreto/1990-1994/d0591.htm. Acesso em 03 out. 2020.

Lei n. 13.005, de 25 de junho de 2014. Aprova o Plano Nacional de Educação - PNE e dá outras providências. Disponível em: http://pne.mec.gov.br/18planos-subnacionais-de-educacao/543-plano-nacional-de-educacao-lei-n-13-0052014. Acesso em: 07 out. 2020.

Suspensa norma do município do PR que proíbe ensino sobre gênero e orientação sexual. Portal do STF, 20/06/2017a. Disponível em: http://www.stf.jus.br/portal/cms/verNoticiaDetalhe.asp?idConteudo=347188\&caixaBu sca $=\mathrm{N}$. Acesso em: 08 set. 2020.

STF recebe mais ações contra leis que proíbem ensino sobre gênero e orientação sexual. Portal do STF, 22/06/2017b. Disponível em: http://www.stf.jus.br/portal/cms/verNoticiaDetalhe.asp?idConteudo=347407\&caixaBu sca $=\mathrm{N}$. Acesso em: 08 out. 2020.

. Suspensa norma que proibia abordagem de questões de gênero nas escolas de Palmas (TO). Portal do STF, 27/08/2018. Disponível em: http://stf.jus.br/portal/cms/verNoticiaDetalhe.asp?idConteudo=388055. Acesso em: 08 set. 2020.

Arguição de Descumprimento de Preceito Fundamental (ADPF) 457 GO - Novo Gama. Relator: Min. Alexandre de Moraes, 27 de abril de 2020a. Disponível em: http://www.stf.jus.br/arquivo/cms/noticiaNoticiaStt/anexo/ADPF457.pdf. Acesso em: 08 set. 2020.

Julgadas inconstitucionais leis sobre Escola Livre e proibição do ensino de sexualidade. Portal do STF, 26/08/2020b. Disponível em: http://stf.jus.br/portal/cms/verNoticiaDetalhe. asp?idConteudo=450392\&caixaBusca= N. Acesso em: 08 set. 2020.

CONFERÊNCIA EPISCOPAL PERUANA 1998. A Ideologia do Gênero: seus perigos e alcances. Tradução: Apostolado Veritatis Splendor - C.D.T. Publicado em 09/06/2008.

Disponível em: https://img.cancaonova.com/noticias/pdf/281960_IdeologiaDeGenero_PerigosEAlcan ces_ConferenciaEpiscopalPeruana.pdf. Acesso em: 18 set. 2020. 
CUNHA, L A. A luta pela ética no ensino fundamental: religiosa ou laica? Cadernos de Pesquisa, São Paulo: FCC, v. 39, n. 137, p. 401-419. Ago. 2009. Disponível em: https://www.scielo.br/scielo.php?script=sci_arttext\&pid=S0100-

$15742009000200005 \&$ Ing=pt\&tlng=pt. Acesso em: 03 out. 2020.

- projeto reacionário de educação. Disponível em: http://luizantoniocunha.pro.br/uploads/independente/1-EduReacionaria.pdf. Acesso em: 03 out. 2020.

DIDIER, F Jr. Curso de Direito Processual Civil. Direito probatório, decisão judicial, cumprimento e liquidação da sentença e coisa julgada. V. 2, 2ª . ed. Salvador: JusPodivm, 2008.

FOZ DO IGUAÇU. Emenda à Lei Orgânica no 47, de 03 de maio de 2018. Acrescenta dispositivo à Lei Orgânica do Município de Foz do Iguaçu, vedando a adoção e/ou divulgação de políticas de ensino que tendam a aplicar a ideologia de gênero. Disponível em: https://leismunicipais.com.br/a/pr/f/foz-do-iguacu/emenda-alei-organica/2018/5/47/emenda-a-lei-organica-n-47-2018-acrescenta-dispositivo-alei-organica-do-municipio-de-foz-do-iguacu-vedando-a-adocao-e-ou-divulgacao-depoliticas-de-ensino-que-tendam-a-aplicar-a-ideologia-de-genero. Acesso em: 03 out. 2020.

HÉRITIER, F. O Eu, o Outro e a intolerância. In: BARRET-DUCROCQ, Francoise (Dir.). A Intolerância: Foro Internacional sobre a Intolerância, Unesco, 27 de março de 1997, La Sorbonne, 28 de março de 1997/ Academia Universal das Culturas. Tradução Eloá Jacobina. Rio de Janeiro: Bertrand Brasil, 2000. p. 24-27.

IBGE- Instituto Brasileiro de Geografia e Estatística. Pesquisa Nacional por amostra de domicílios (Pnad). Síntese de indicadores 2015. Rio de Janeiro, RJ: IBGE, 2015.2 Disponível em: https://biblioteca.ibge.gov.br/visualizacao/livros/liv98887.pdf . Acesso em: 18 set. 2020.

LAURINDO, J. Após pressão de deputados, Moisés decide retirar termos sobre identidade de gênero de currículo da educação de SC, 28/08/2019a. Disponível em: https://www.nsctotal.com.br/noticias/apos-pressao-de-deputados- moisesdecide-retirar-termos-sobre-identidade-de-genero-de. Acesso em 07 set. 2020.

. Deputados pressionam para a retirada do termo „identidade de gênero" de currículo base de SC, 28/08/2019b. Disponível em: https://www.nsctotal.com.br/noticias/deputados-pressionam-para-retirada-de-termoidentidade-de-genero-de-curriculo-base-de-sc. Acesso em 07 set. 2020.

LÜDKE, M.; A, M. E. A. Pesquisa em educação: abordagens qualitativas. São Paulo: EPU, 1986.

MARTINS, L. M. O Desenvolvimento do Psiquismo e a Educação Escolar: contribuições à luz da psicologia histórico-cultural e da pedagogia histórico-crítica, Campinas: Autores Associados, 2013. 
MIRANDA, J. Nos dez anos de funcionamento do tribunal constitucional. In: BRITO, José de Sousa e. et al. Legitimidade e legitimação da justiça constitucional. Coimbra: Coimbra Editora, 1995. p. 91-104.

MOVIMENTO ESCOLA SEM PARTIDO. Atuando desde 2004, o Movimento Escola sem Partido é reconhecido nacionalmente como a mais importante e consistente iniciativa contra o uso das escolas e universidades para fins de propaganda ideológica, política e partidária. Disponível em: https://www.escolasempartido.org/. Acesso em: 07 out. 2020.

MURSELL, J. Principles of Democratic Education. New York: Norton. 1955.

NOVO GAMA. Lei 1.516, de 30 de junho de 2015. Proíbe material com informação sobre ideologia de gênero nas escolas municipais de Novo Gama - GO e dá outras providências.

Disponível

em:

https://acessoainformacao.novogama.go.gov.br/legislacao/lei/id=49. Acesso em: 07 out. 2020.

PAULO, V; ALEXANDRINO, M. Direito Constitucional Descomplicado. 16. ed., Forense: Rio de Janeiro-RJ. Método: São Paulo-SP,2017.

PENNA, F. O ódio aos professores. In: Ação Educativa Assessoria, Pesquisa e Informação (Org.). A ideologia do movimento Escola Sem Partido: 20 autores desmontam o discurso. São Paulo: Ação Educativa, 2016. p. 93-100.

PINHA, D. Ampliação e veto ao debate público na escola: História Pública, ensino de História e o projeto "Escola Sem Partido". Revista TransVersos: "Dossiê: História Pública: escritas contemporâneas de História, Rio de Janeiro: UERJ, v. 07, p. 11-34, 03 set. 2016.

PORTAL SUL21. Câmara de Xangri-lá (RS) torna obrigatória leitura da bíblia nas escolas municipais. Disponível em: https://www.sul21.com.br/cidades/2020/09/camara-de-xangri-la-rs-torna-obrigatorialeitura-da-biblia-nas-escolas-municipais/. Acesso em: 18 set. 2020.

PORTAL JUSTOCANTINS. Prefeitura de Palmas se manifesta sobre liminar do STF sobre suspeição aos efeitos da lei municipal. Disponível em: https://www.justocantins.com.br/noticias-do-estado-46631-prefeitura-de-palmas-semanifesta-sobre-liminar-do-stf-sobre-suspensao-aos-efeitos-de-lei-municipal.html. Acesso em: 07 out. 2020.

RICCEU, P. Etapa atual do pensamento sobre a intolerância. In: BARRETDUCROCQ, Francoise (Dir.). A Intolerância: Foro Internacional sobre a Intolerância, Unesco, 27 de março de 1997, La Sorbonne, 28 de março de 1997/ Academia Universal das Culturas. Tradução Eloá Jacobina. Rio de Janeiro: Bertrand Brasil, 2000. P. 20-23. 
SANTA CATARINA. Plano Estadual de Educação - 2015-2024. Primeira versão de 16/06/2015a. Disponível em: http://www.sed.sc.gov.br/documentos/plano-estadualde-educacao-sc-452. Acesso em: 12 out. 2020.

Lei n. 16.794, de 14 de dezembro de 2015b. Aprova o Plano Estadual de Educação (PEE) para o decênio 2015-2024 e estabelece outras providências. Disponível em: http://leis.alesc.sc.gov.br/html/2015/16794_2015_lei.html. Acesso em: 07 out. 2020.

Currículo Base da Educação Infantil e do Ensino Fundamental do Território Catarinense/ Estado de Santa Catarina. Florianópolis: Secretaria de Estado da Educação, 2019.

SCOTT, J. Gênero: Uma categoria útil para análise histórica. Educação \& Realidade. Porto Alegre: UFRGS, v. 20, n. 2, p. 71-99, jul./dez. 1995.

SILVA, T. T. da. A Produção Social da Identidade e da Diferença. In: SILVA, Tomaz Tadeu da (Org.). Identidade e diferença: a perspectiva dos estudos culturais. Petrópolis: Vozes, 2014. p. 73-102.

SINDICATO NACIONAL DOS DOCENTES DAS INSTITUIÇÕES DE ENSINO SUPERIOR. Et al. Manual de Defesa Contra a Censura nas Escolas. Disponível em: https://www.manualdedefesadasescolas.org/manualdedefesa.pdf. Acesso em: 05 out. 2020.

TORRIGLIA, P. L.; ORTIGARA, V. O campo das mediações: primeiras aproximações para a pesquisa em políticas educacionais. In: CUNHA, C. da; SOUZA, J. V de; SILVA, M. A. da (Org.). O método dialético na pesquisa em educação. Campinas: Autores Associados, 2014. p. 180- 200.

VENCESLAU, P; LAGUNA, E. Malafaia diz que evangélicos não negociarão "ideologia de gênero". Revista Exame, 17/08/2017. Disponível em: https://exame.com/brasil/malafaia-diz-que-evangelicos-nao-negociarao-ideologia-degenero/. Acesso em 18 set. 2020. 